\title{
(Re)organização social, hegemonia e intervenção humanitária: uma visão gramsciana da guerra do Iraque ${ }^{1}$
}

Fernando José Ludwig²

\section{Resumo}

O presente artigo visa explorar até que ponto a interação entre os conceitos gramscianos de sociedade civil e sociedade política (que, por sua vez, consistem na base da conceptualização de hegemonia de Gramsci) é importante para se estabelecer um certo nível de segurança e, consequentemente, pode ser visto enquanto instrumento de prevenção/resolução de conflitos. Nesse sentido, a reestruturação socioeconomica imposta pela intervenção norte-americana levou uma completa falta de autonomia da sociedade iraquiana face a seu próprio governo. Assim, o presente trabalho argumenta que um dos pontos fundamentais para se alcançar um determinado nível de paz é ter em conta a questão da organização de projetos hegemônicos no interior das sociedades civis, e assim reorganizar sua representatividade.

Palavras-chave: Hegemonia. Gramsci. Intervenção. Paz. Iraque.

\section{Introdução}

Perante a complexidade do atual cenário internacional, torna-se cada vez mais necessária a incursão da sociedade civil e, consequentemente, sua relação com a sociedade política, para a compreensão das conflitualidades, violências e

\footnotetext{
${ }^{1}$ Texto apresentado na Conferência Internacional World Conference of Humanitarian Studies, Groningen, Holanda, 4 - 7 de Fevereiro de 2009. Título original: "Social (re)organizations, hegemony and humanitarian intervention: towards a gramscian comprehension of the Iraq war".

${ }^{2}$ Licenciado em Relações Internacionais pela Universidade de Coimbra (Portugal); mestre em Relações pela University of Kent, Reino Unido; e actualmente é doutorando em Política Internacional e Resolução de Conflitos pela Faculdade de Economia da Universidade de Coimbra/Centro de Estudos Sociais (Portugal) - fernandoludwig@ces.uc.pt.
} 
guerras que assolam todo o mundo. Para esse efeito, é preciso ter uma visão mais ampla do conceito tradicional de guerra apresentada por Clausewitz como sendo a continuação da política por outros meios (CORREIA, 2002, p. 23), alargando assim o espectro da guerra, onde novos agentes, objectivos, meios e fins aparecem no cenário da conflitualidade.

Assim sendo, o presente trabalho tem um objetivo duplo. Em primeiro lugar, à luz do conceito de hegemonia de Gramsci, apresentar quais são as consequências de se analisar a interação entre sociedade civil e sociedade política (como forma de reorganização social) enquanto fator fundamental para se estabelecer um projeto de reconciliação no tecido social em causa e, consequentemente, consolidar o(s) processo(s) de paz. Já num segundo momento, o presente trabalho visa analisar de que forma intervenção humanitária pode ser uma ferramenta útil para a reconstrução (tendo como ambição a reestruturação) social.

Para tal efeito, decidiu-se examinar essencialmente a condução da Guerra do Iraque. Desse modo, metodologicamente, embora essa separação não seja linear, tomaremos como nossa variável independente a globalização das novas conflitualidades e suas repercussões na resolução dos conflitos, e como variáveis dependentes a leitura gramsciana do conceito de hegemonia enquanto forma de compreender a reorganização social e a intervenção militar humanitária e suas reflexões na reconstrução social, tendo como fim principal a estabilidade relativa.

Visando essencialmente atingir os objectivos supra mencionados, o presente ensaio estará dividido em duas secções. A primeira visa estabelecer um nexo causal entre a guerra do Iraque e a importância da formação social enquanto factor de coesão social e, consequentemente, de um determinado nível de paz. Em segundo lugar, pretende-se identificar as principais características do conceito de hegemonia em Gramsci e sua importância para os estudos da paz, essencialmente no âmbito das novas guerras. Ao mesmo tempo, visa-se explorar até que ponto tal abordagem pode ou não ser importante para a eficiência e legitimidade das intervenções no tocante à sua função matricial, ou seja, restabelecer os padrões de paz aceites pela comunidade internacional. Num terceiro e final momento, o presente ensaio tem como objetivo analisar os efeitos da abordagem teórica realizada num primeiro momento e aplicá-la ao contexto do conflito iraquiano. 


\section{Hegemonia e reorganização social: uma visão gramsciana}

O conceito de hegemonia pode ser apresentado de diferentes formas e com distintos significados de acordo com os objetivos e interesses da aplicação em causa. De fato, há uma inerente incapacidade do analista político em se abstrair de valores e conceitos que são partes integrantes do seu juízo de valores (seguindo assim o pensamento kantiano). Indo além e seguindo os pressupostos dos partidários da teoria crítica, toda e qualquer tentativa de se estabelecer axiomas que expliquem efetivamente comportamentos constantes em diferentes situações está a servir para algum objetivo e interesse final de alguém, como menciona Robert Cox "theory is always for someone and for some purpose" (COX, 1981, p. 128). Nesse sentido, a presente seção tenciona não ser isenta de qualquer juízo de valores, mas sim apresentar de forma explícita o conjunto de premissas encontradas na teoria gramsciana de maneira - propositada - a explorar a(s) possibilidade(s) de as aplicar aos estudos da paz.

O presente ensaio advoga a importância da reorganização social à luz das relações sociais de poder que é, consequentemente, entendida aqui por meio do conceito de hegemonia. Desse modo, um dos maiores contributos nesse sentido foi realizado por Gramsci, que visou compreender em que aspectos as classes dominantes usam da estrutura social para manter e/ou alcançar o poder e, consequentemente, a (contra)reação das chamadas classes subalternas. Tal leitura dos textos de Gramsci permite-nos aplicar alguns princípios nos presentes casos das novas conflitualidades (KALDOR, 1999; MOURA, 2005), do século XXI, que aponta cada vez mais para uma análise intraestatal das razões ou "soluções" dos conflitos.

Assim sendo, para os termos presentes no presente ensaio, tomaremos a hegemonia como sendo uma série de características, que se utilizam de determinados instrumentos, que um determinado grupo social possui. Estas características lhe permite influenciar ou determinar o comportamento de outros grupos, baseado essencialmente na sua coesão social, bem como na sua capacidade relativa de poder (político, militar e económico).

António Gramsci, filósofo italiano do início do século XX, vai repensar os conceitos marxistas de dominação, mas efetivamente atribui uma crítica mais concisa aos feitos de Lênin, quando tentou aplicar tais conceitos. Todavia, por se tratar 
de um autor neo-marxista, para se compreender Gramsci, é necessário ao menos abordar (sempre de forma reduzida) os principais pressupostos do marxismo, necessariamente no que diz respeito à questão da hegemonia entre classes subalternas (proletariados) e os detentores dos modos de produção (burguesia). Assim sendo, na tentativa de transpor o pensamento marxista para o âmbito das relações internacionais, as relações inter-estatais estariam diretamente relacionadas com a capacidade produtiva de cada estado, como afirma Marx,

The relations of various nations with one another depend upon the extent to which each of them has developed its productive forces, the division of labour, and domestic commerce ... not only the relations of one nation to others, but also the entire internal structure of the nation itself depends on the stage of development achieved by its production and its domestic and international commerce' (MARX apud SIMON, 1994, p.108).

Podemos verificar que nesta percepção das relações tanto sociais quanto internacionais há um certo mecanicismo, determinismo que menospreza qualquer tipo de reorganização social que não tenha o econômico como matriz principal. Ou seja, qualquer visão das relações sociais e internacionais que não tivesse como foco principal as relações econômicas de poder, seria reducionista. E é justamente nesse aspecto que se encontra a maior crítica de Gramsci ao pensamento marxista, que se assenta essencialmente na recusa desse rigoroso determinismo científico da análise social, a isso Gramsci chama de materialismo vulgar.

Quando afirma que "tudo é política, inclusive a filosofia ou as filosofias; e a única filosofia é a história em ato, ou seja, a própria vida" (GRUPPI, 1978, p. 1), Gramsci faz uma ruptura entre a concepção de história e filosofia que lhe permite ir além dos ideários filosóficos à prática política (ou ação revolucionária) que, por sua vez, inclui no pensamento analítico da realidade hegemônica social outros factores senão o econômico. E é através desta particular noção e importância atribuída à história - derivada de Georges Sorel (COX, 1983) - que Gramsci concebe a noção de que a interatividade entre a estrutura (econômica) e a super-estrutura (política e social) evita o reducionismo econômico, formando assim o que chama de blocco storico. É justamente a partir desta dialética entre o reducionismo econômico (ou determinismo mecânico) e o papel da história que permite Gramsci edificar seu conceito de hegemonia. Paralelamente, Robert Bocock (1986) advoga 
que estas acepções são importantes para uma análise metodológica (para que seja viável sua análise teórica). Neste sentido, é importante salientar que Gramsci não exclui a vertente econômica, mas sim dá mais valor às questões culturais, políticas e sociais do cenário interno dos Estados (BOCOCK, 1986). Para o filósofo, o conceito de bloco histórico tem uma vertente revolucionária (semelhante à revolução encontrada em sua época - e.g., a revolução bolchevique), onde a transformação (transformismo) desta estrutura formada pelas esferas políticas, sociais e econômica somente poderia ser substituída por uma outra capaz de igual ou superior características. Deste modo, não é possível existir um bloco histórico sem a existência de uma classe dominante. Por conseguinte, antes de seguirmos para os mecanismos de manutenção das classes hegemônicas, é fundamental compreender que a noção de poder em Gramsci se divide em "dominação" e "liderança moral e intelectual" (ARRIGHI, 1993), que remonta a figura mitológica apresentada por Maquiavel do centauro, em que a prática política se resume a interação entre coesão e consenso. Este ponto é fundamental para uma análise gramsciana da coesão social (conseguida por meio da formação de consenso e da prática coerciva), a partir da qual se torna possível obter uma relativa estabilidade social.

No entanto, para que essa classe dominante se mantenha no poder (para além de já "dever" exercer liderança) é necessário que disponha de alguns mecanismos de formação de consenso. Estes princípios estão descritos na principal obra de Gramsci Cadernos do Cárcere, que foi feita quando de sua detenção entre 1929 e 1935, na qual podemos encontrar uma constante nos trabalhos de Gramsci. Toda sua análise parte da compreensão ou derivam da questão de hegemonia (GRUPPI, 1978, p. 65). A construção da formação intelectual faz parte da essência do conceito hegemonia em Gramsci, assim sendo as classes subalternas tem uma concepção do mundo que é diretamente elaborada pelas classes dominantes. Assim sendo, segundo Gramsci, os canais pelos quais as classes dominantes constroem sua influência ideal (ou seja, sua capacidade de difundir seus valores ideais) passam pelo controle da escola, da religião, do serviço militar, dos jornais (imprensa) locais, regionais e nacionais, por manifestações culturais, folclore, etc. Deste modo, ocorre a formação do consenso, em que os grupos dominantes se utilizam destes meios estruturais da sociedade para validar seus interesses e ideias próprios. 
De forma sintética, Gramsci argumenta que "a hegemonia, portanto, não é apenas política, mas também um fato cultural, moral, de concepção do mundo" (GRUPPI, 1978, p. 73). Tal concepção exige uma sociedade civil organizada, com laços comuns, capaz de exportar seus interesses para outras sociedades.

Um último aspecto que merece atenção nos princípios de Gramsci, e que também pode ser posteriormente discutido no caso do conflito iraquiano, está naquilo que o autor chama de guerra de movimento e guerra de posição, que são necessariamente complementares. No primeiro caso, a guerra de movimento, tendo como base o contexto histórico da Europa de sua época, se refere essencialmente ao momento expansionista de um sociedade (ataque). Em suas notas, Gramsci apresenta como exemplo a política da revolução francesa (1789-1793). Ao mesmo tempo, classifica como sendo guerra de posição àquela que visa defender ou manter sua posição, também exemplificado através do longo período deste tipo de guerra que se deu na Europa entre 1815 e 1870 (GRUPPI, 1978, p.138-139).

Dito isto, a noção de hegemonia passa a incorporar aspectos singulares, que vão além de sua visão tradicional, evitando assim que sua interpretação seja empregada de forma errônea. Um ponto a salientar neste sentido, e mesmo para elevar os conceitos supramencionados à atualidade, Jonathan Joseph (2001; 2008) propõe duas visões distintas referentes à hegemonia. A primeira delas tem a ver com visão realista de hegemonia, isto é, aquela entendida como forma de dominação de um determinado grupo sobre outro(s) grupos(s). Em segundo lugar, há uma outra visão que advoga que este tipo de dominação é produto de fatores sócio-econômicos que se embasam na formação de consenso (JOSEPH, 2002, p. 1; JOSEPH, 2008). Seguindo ainda a definição deste autor, o mesmo apresenta a dualidade da hegemonia, baseando-se na definição de power 1 e power2 de Bhaskar (BHASKAR, 1993 apud JOSEPH, 2002), em que apresenta duas formas fundamentais que variam de acordo com seus objetivos alusivos à sociedade em questão, conforme afirma,

Structural hegemony and surface hegemony are two aspects of a continual process. Structural hegemony concerns the deep, underlying condition within society and the union of the social formation. Surface hegemony concerns the actual hegemonic projects that arise out of this situation it represents a manifestation of the underlying conditions, albeit, with its own character and dynamics (JOSEPH, 2002, p. 131). 
Com o intuito de clarificar essa distinção entre hegemonia estrutural e superficial (ou seja, essa dualidade), o autor apresenta de forma sumarizada e detalhada o quadro abaixo.

Quadro 1 - A dualidade da hegemonia

\begin{tabular}{|c|c|}
\hline Structural hegemony & Surface hegemony \\
\hline Deep & Actual \\
\hline Functional & Manifest/realised \\
\hline Structural & Agential \\
\hline Secures unity of social formation & $\begin{array}{l}\text { Hegemonic activities, projects and } \\
\text { practices }\end{array}$ \\
\hline $\begin{array}{l}\text { Reproduction of social structures and } \\
\text { structural ensembles }\end{array}$ & $\begin{array}{l}\text { Emergent from underlying structures } \\
\text { (but with their own powers and } \\
\text { dynamics) }\end{array}$ \\
\hline Underlying conditions & Conscious political expression \\
\hline Reproduction & Struggle \\
\hline Social cement & Coercion and Consent \\
\hline $\begin{array}{l}\text { Largely unconscious structural } \\
\text { reproduction }\end{array}$ & $\begin{array}{l}\text { Conscious transformation, } \\
\text { conservation or political advancement }\end{array}$ \\
\hline
\end{tabular}

Fonte: JOSEPH (2002, p. 131).

Perante tal dualidade, o que se busca - e esta é mais comumente encontrada em sociedades mais desenvolvidas e, consequentemente, mais complexas - é efetivamente estabelecer que a relação agente/estrutura passe pela solidificação de um determinado grupo (ou conjunto de grupos) enquanto hegemônicos estruturais. Desse modo, é possível estabelecer (em determinados casos reestabelecer) a ordem social. Veremos mais a frente como o conceito de bloco histórico sustenta tal afirmação.

Uma vez explorados os principais aspectos da teoria hegemônica de Gramsci, bem como seus autores mais recentes, e tendo em causa o presente tema, a seguinte seção é destinada essencialmente a analisar suas implicações no contexto do regime estabelecido posteriormente a queda do governo de Saddam Hussein, em 2003. 


\section{Intervenção: Iraque, a reconstrução e o processo de paz}

O tema “intervenção" per se é algo que merece uma atenção especial devido às suas implicações e contradições morais e legais no seio do sistema internacional. Entretanto, dada as restrições espaciais e seguindo os objetivos propostos, a presente seção visa estritamente explorar os efeitos da invasão iraquiana na reconstrução e reestruturação de sua sociedade civil, essencialmente à luz da representatividade. Por se tratar de um tema em constante evolução, não é visado apresentar respostas ou soluções para os problemas sociais iraquianos, mas sim explorar de que maneira a condução dessa reconstrução poderá influenciar os trâmites necessários para se estabelecer a cessação do conflito armado nesse país (ou seja, um determinado nível de paz). Assim sendo, a presente seção tem como objetivo, num primeiro momento, contextualizar o processo de reconstrução da camada social iraquiana e, em segundo lugar, efectivamente analisar em que medida essas políticas, juntamente com os efeitos da presença norte-americana no terreno, vão ao encontro das propostas apresentadas na secção anterior acerca do conceito de hegemonia e sua possível aplicabilidade para se compreender fenômenos sociais em prol de uma estabilização do conflito.

Dadas as inúmeras vicissitudes desse particular conflito, tomaremos em conta somente aqueles que de certa forma são fundamentais para o presente ensaio. Uma das características do conflito iraquiano está no fato de ele não se enquadrar numa situação de pós-conflito, apesar da declaração do Pentágono acerca do fim da guerra em 2004, em que afirma que 'major combat engagements are over' (KAGAN, 2003, p. 3). Esse aspecto se torna importante, pois ainda não estão definidos seus estratos sociais, impossibilitando assim a presença de um hegemônico local. Parece-me evidente e consensual que o conflito iraquiano é produto de um determinado contexto da política internacional, nomeadamente da dramática mudança ocorrida na política externa dos Estados Unidos após os atentados de 11 de Setembro de 2001 (BARAKAT, 2005a). É de se notar que, diferentemente das intervenções ocorridas no Afeganistão e no Kosovo por exemplo, marcadas pelo suporte da comunidade internacional, há uma decisão unilateral por parte da superpotência de se invadir o Iraque com uma inobservância às posições da comunidade internacional (nomeadamente da União Europeia e das Nações Unidas). 
Ao transpor esse acontecimento para os parâmetros hegemônicos de Gramsci, poderíamos classificar que esse primeiro momento, quando da invasão, como sendo uma guerra de movimento. É de se notar que, apesar das dificuldades alusivas a representação da sociedade civil, não podemos classificar que o Iraque era um estado pária (BARAKAT, 2005b) e funcionava relativamente bem, essencialmente em razão de suas riquezas naturais (petróleo). É ainda necessário ressaltar aqui uma evolução conceptual da percepção do conceito de ameaça, que passa essencialmente pela aplicação do conceito de guerras preemptivas. ${ }^{3}$

Assim sendo, evidentemente que a política externa norte-americana, após a intervenção, estaria no comando da reconstrução social, econômica e cultural do país. Vimos aqui um dos primeiros pontos que podem ser visualizados a luz da teoria gramsciana. Ora, se a formação do bloco histórico está condicionado à existência de uma classe dominante dentro da sociedade, evidentemente que essa classe deve ser (ou pelo menos deveria ser) nacional que, nesse caso, seriam os iraquianos. Como exemplifica Dodge (2005), acerca da abertura da imprensa e dos meios de comunicação (ou seja, o controle da opinião pública) depois do fim do regime totalitário de Saddam:

The US was faced with a dilemma: public opinion was demanding that it build government institutions that were stable, efficient and sustainable but this was matched with increasing calls that it should primarily be Iraqis who managed this process. But which Iraqis should fill this role and how they should be chosen was not at all clear (DODGE, 2005, p. 708)

Embora esse seja um exemplo pontual, advogo que um dos pontos fundamentais das chamadas intervenções "humanitárias" está justamente em conseguir estabelecer uma transição de poder pacífica que, efectivamente, dê representatividade para os grupos locais, a fim de formarem (ou reorganizarem) seus laços sociais, conforme aponta Brown:

\footnotetext{
${ }^{3}$ Nesse sentido, Sofaer apresenta quatro requisitos básicos para se identificar uma guerra preemptiva, são eles "the nature and magnitude of the threat involved; the likelihood that the threat will be realized unless preemptive action is taken; "the availability and exhaustion of alternatives to using force; and whether using preemptive force is consistent with the terms and purposes of the UN Charter and other applicable international agreements" (SOFAER, 2003, p. 220).
} 
The importance of equitable local participation in all aspects of reconstruction planning and implementation overrides often-inflated debates over whether the development intervention should be civilian or military in nature (BROWN, 2005, p. 774).

Ou Barakat (2005, p. 587) "Iraq's reconstruction requires a multifaceted programme but one that always has people and their perceptions in the forefront"

Entretanto, o próximo desafio dos Estados Unidos estaria em solidificar as instituições políticas que foram dramaticamente destruídas com o fim do regime totalitário. Nesse sentido, a fim de se restabelecerem as funções administrativas e governamentais do estado iraquiano, foi instaurada, a serviço dos EUA, a primeira Coalition Provisional Authority (CPA) que tinha, por sua vez, quatro pilares fundamentais: justiça, segurança, governança e infraestrutura (BROWN, 2005, p. 761). Nesse sentido, era suposto que um dos principais corolários da reestruturação da infraestrutura política ajudasse no desenvolvimento da economia desse país, ponto que ficou claramente ofuscado ao longo do conflito. Assim, houve uma clara desconexão entre as infraestruturas e a população civil, evitando que houvesse uma solidificação da infraestrutura de forma sustentável (BROWN, 2005, p. 761), ou seja, optou-se por uma reconstrução "de cima para baixo" (top-down). E essa sustentabilidade está diretamente ligada com visão da sociedade em relação ao seu governo (por exemplo, a questão da corrupção) que, por sua vez, delimita diretamente tanto a segurança econômica do país quanto a segurança humana (COCKELL, 2000 apud BROWN, 2005, p. 762). Posteriormente, agora em conjunto com as Nações Unidas, o governo norte-americano decidiu implementar, ainda sob a tutela da CPA, o Iraqi Governing Council (IGC), que tinha como objetivo estreitar os laços entre autoridades religiosas, tribos e outras autoridades regionais e a nova autoridade governamental. No entanto, apesar dos esforços, a capacidade desse organismo em trazer estabilidade e legitimidade para o governo iraquiano é fortemente questionável.

Contudo, o fracasso de tais projetos por parte das iniciativas norte- americanas e das Nações Unidas incidiu essencialmente na falta de uma incisão mais ativa nas regiões mais pobres do Iraque, onde infraestruturas básicas (saneamento básico, água potável etc.) não caracterizaram prioridades dessas políticas, bem 
como no seguinte problema em ser um órgão responsável pela reconstrução e ao mesmo tempo representar os interesses das comunidades locais. Nesse sentido, Dodge (2005, p. 718-719) argumenta em favor de uma posição que é partilhada pelo trabalho, que "the US occupation of Iraq failed spectacularly to build even the foundations of the infrastructural power [...] the main reasons for this failure are ideological", e ainda aponta os resultados de tal fracasso, como "the result of this failure is the security vacuum that casts a shadow over the south and centre of the country and dominates the Iraqi population's everyday lives".

Entretanto, mesmo com todo o aparato militar dos EUA, quais seriam as razões pelas quais todo esse desenvolvimento não consegue efetivamente fazer face a esses novos tipos de conflitualidade (leia-se: novas guerras) e, especificamente, pôr termo ao conflito iraquiano? Uma das possíveis respostas para essa questão está no fato de este desenvolvimento estar basicamente voltado às questões tecnológicas e econômicas, colocando de lado, conforme supramencionado, as questões sociais, políticas e culturais, voltado para a reconstrução do tecido social. Mais uma vez, advogamos que tais pontos devem ser considerados quando se decide intervir.

Vimos até o momento que há essencialmente dois fatores que impedem a reconstrução, de forma sustentável, do tecido social iraquiano. O primeiro deles é o mais evidente, a presença de uma administração estrangeira (nesse caso, os EUA) no país evita a formação de grupos sociais capazes de formar consenso ou mesmo de utilizar das estruturas sociais para tal efeito. Esse é um ponto fundamental, a falta de representatividade na heterogênea sociedade civil iraquiana. Nesse sentido, Dodge (2005, p. 720) argumenta acerca da presença norte-americana que "[...] successful state building in Iraq would need the resources, expertise and neutrality that only the UN might possibly be able to deliver". O segundo fator está relacionado aos níveis de conflitualidade, e também é derivado do fato da invasão ainda estar em curso, que assola a sociedade. Evidentemente, que não são respostas claras e únicas capazes de responder quais seriam os melhores caminhos a seguir para se chegar a cessação da violência nesse contexto, no entanto é possível sim atentar para o fato de que a sociedade civil iraquiana - embora muito fragilizada - deveria ser mais ouvida durante o processo de reconstrução social. 


\section{Conclusão}

Ao longo do presente ensaio tentamos identificar quais foram os principais aspectos da teoria hegemônica de Gramsci e sua relevância para os estudos da paz e do conflito, tendo como estudo de caso a Guerra do Iraque. Como referimos, a intenção aqui não é encontrar soluções concretas e universais para o comportamento de instituições internacionais, mas sim evidenciar o fato da importância de se estabelecer uma sociedade civil sólida e coesa.

E é nesse novo contexto de conflitualidade e no desenvolvimento militar que se encontra uma certa decepção em relação aos seus resultados finais, ficando assim aquém das expectativas empregadas pelo país referência nesse assunto, ou seja, os EUA. Ao longo do trabalho, apontaram-se os principais desenvolvimentos tanto da formação social (ou falta dela) quanto da incapacidade de resposta do poderio militar da força conjunta (dos países desenvolvidos) em responder as ameaças apresentadas por determinados grupos da sociedade civil iraquiana. Assim sendo, podemos afirmar que as estratégias até então utilizadas em termos militares, podem e devem ser drasticamente reformuladas a fim de responder ao conceito de novas guerras (ou novos conflitos), nas quais a violência dentro da sociedade civil é tomada como fator fundamental. Em suma, a própria razão ontológica do presente trabalho, ou seja, o desafio da organização social enquanto função da paz, ou pelo menos, é plausível afirmar que, no contexto iraquiano, não se obteve qualquer tipo de sucesso em termos de paz e cessação de conflitos internos.

Entretanto, com o intuito de concluir a linha de pensamento proposto pelo presente trabalho, outros aspectos merecem alguma atenção, e têm a ver com a intervenção dos EUA e suas repercussões no tecido social iraquiano. Conforme dito, podemos afirmar que se trata de uma guerra de movimento. Foi deliberadamente uma decisão dos EUA em destruir um regime que (apesar de todas os defeitos e contravenções praticadas por tal regime) funcionava e identificava relativamente bem as classes dominantes (seus canais de influência), como afirma Gramsci "a supremacia de um grupo social se manifesta de dois modos, como dominação e como direção intelectual e moral" (GRUPPI, 1978, p. 78), ou seja, é preciso haver uma classe dominante para que se forme o bloco histórico. Desse modo, a invasão norte-americana no território iraquiano rapidamente se encarregou de destruir por completo a antiga organização social do país, pensando somente em suas reformas econômicas, impossibilitando assim a 
formação de representatividades capazes de exercerem sua hegemonia mediante a formação de um bloco histórico. Por fim, um último fator diz respeito às atuais estruturas políticas iraquianas que servem aos interesses da superpotência e não aos interesses do tecido social local, consequentemente há uma desordem na definição dos grupos tanto hegemônicos quanto contra-hegemônicos locais, onde todos lutam para que o(s) "invasor(res)" se retirem. Desse modo, impede-se que haja uma estabilidade relativa.

\section{Social (re)organizations, hegemony and humanitarian intervention: towards a gramscian comprehension of the Iraq war.}

\section{Abstract}

This article seeks to explore to what extent the interaction between the Gramscian concepts of "political" and "civil" society (that consists the basis of Gramsci's conceptualization of hegemony) are important to establish a security environment and, consequently, could be understood as an instrument of conflict prevention and/or resolution. In spite of this, the socio-economic re-arrangement imposed by the US intervention led to a complete lack of Iraqis societal autonomy and representation. Therefore, it is argued that the starting point to reach a reasonable level of "peace" is necessary first to bear in mind the quest of hegemonic projects within societies, and thus re-organizes its representativeness.

Keywords: Hegemony. Gramsci. Intervention. Peace. Iraq.

\section{Referências}

ARRIGHI, Giovanni.The three hegemonies of historical capitalism. In: GILL, Stephen (Ed.). Gramsci, historical materialism and international relations. Cambridge: Cambridge University, 1993. p. 149-185.

BHASKAR, Roy. Dialectic: the pulse of freedom. Londres: Verso Books, 1993.

BROWN, Richard H. Reconstruction of Infrastructure in Iraq: end to a means or means to an end? Third World Quarterly, [S.1.], v. 26, n. 4-5, p. 759-778, 2005.

BROWN, Richard H. Reconstruction of Infrastructure in Iraq: end to a means or means to an end? Third World Quarterly, [S.1.], v. 26, n. 4-5, p. $759-775,2005$. 
BUSH, George W. Bush makes historic speech aboard warship. CNN, 01 maio 2003. Disponível em: <http://www.cnn.com/2003/US/05/01/bush. transcript/>. Acesso em: 29 jan. 2009.

CORREIA, Pedro Pezarat. Manual de geopolítica e geoestratégia: conceitos, teorias e doutrinas. Coimbra: Quarteto, 2002. v. 1.

COX, Robert W. Gramsci, hegemony and international relations: an essay in method. In: GILL, Stephen (Ed.). Gramsci, historical materialism and international relations. Cambridge: Cambridge University, 1993. p. 49-66.

COX, Robert W. Social forces, states and world orders: beyond International Relations theory. Journal of International Studies, [S.1.], v. 10, n. 2, 1981, p. 126-155.

DODGE, Toby. Iraqi Transitions: from regime change to state collapse. Third World Quarterly, [S.1.], v. 26, n. 4-5, p. 705 - 721, 2005.

GRUPPI, Luciano. O conceito de hegemonia em Gramsci. Rio de Janeiro: Graal, 1978.

JOSEPH, Jonathan. Hegemony and the structure-agency problem in International Relations: a scientific realist contribution. Review of International Studies, [S.l.], v. 34, p.109-128, 2008.

JOSEPH, Jonathan. Hegemony: a realist analysis. London: Routledge, 2002.

KAGAN, F. War and aftermath. Policy Review, [S.1.], v. 10, p. 3-27,2003.

KALDOR, Mary. New and old wars: organized violence in a global era. Cambridge: Polity Press, 1999.

MOURA, Tatiana. Novíssimas guerras, novíssimas pazes. Desafios conceptuais e políticos. Revista Critica de Ciências Sociais, [S.1.], n. 71, p. 77-96, 2005.

RATTON, M. Post-Saddam Iraq: deconstructing a regime, reconstructing a nation. Third World Quarterly, [S.1.], v. 26, n. 4-5, p. 571- 591, 2005b,

RATTON, M. Reconstructing Post-Saddam Iraq: an introduction. Third World Quarterly, [S.l.], v. 26, n. 4-5, p. 565-570, 2005a.

SOFAER, Abraham D. On the necessity of pre-emption. European Journal of International Law, [S.1.], v. 14, n. 2, 2003. 